\title{
Determinants of Brain Natriuretic Peptide Levels in Patients With Lone Atrial Fibrillation
}

\author{
Sang Hak Lee, MD; Jae-Hun Jung, MD; Seung-Hyuk Choi, MD; \\ Namho Lee, MD; Woo-Jung Park, MD; Dong-Jin Oh, MD; \\ Chong-Yun Rhim, MD; Kwang-Hwak Lee, MD
}

\begin{abstract}
Background Although brain natriuretic peptide (BNP) is increasingly being used for screening and monitoring of congestive heart failure, its utility in patients with lone atrial fibrillation $(\mathrm{AF})$ is unclear.

Methods and Results Plasma BNP levels were measured and comprehensive transthoracic echocardiography was performed in 96 subjects (47: sinus rhythm, 49: AF). Patients with structural heart disease were excluded. Potential determinants of BNP levels were identified by univariate and multivariate analyses. Individuals with AF had higher BNP levels than those with sinus rhythm $(150 \pm 114$ vs $49 \pm 61 \mathrm{pg} / \mathrm{ml}, \mathrm{p}<0.001)$ The left atrial (LA) volume index $(r=0.63, p<0.001)$, the pulmonary artery systolic pressure $(r=0.45, p=0.006)$, and the early mitral inflow velocity $(\mathrm{E}) / \mathrm{mitral}$ annular velocity $\left(\mathrm{E}^{\prime}\right)(\mathrm{r}=0.36, \mathrm{p}=0.04)$ were found to be independently correlated with BNP level. The correlations between BNP level and LA volume index $(p=0.001)$ or $E / E^{\prime}(p=0.03)$ were unaltered when subjects with sinus rhythm were removed from the analysis.

Conclusions BNP levels significantly correlated with LA volume index and E/E' in patients with lone AF, which indicates that the BNP level may reflect early left ventricular dysfunction and LA enlargement in this patient population. (Circ J 2006; 70: 100-104)
\end{abstract}

Key Words: Atria; Atrial fibrillation; Brain natriuretic peptide; Hemodynamic process

$A$

trial fibrillation $(\mathrm{AF})$ is a common arrhythmia and an independent predictor of mortality! Moreover, it is known to cause left ventricular (LV) dysfunction in patients with or without structural heart disease ${ }^{2,3}$

The serum level of brain natriuretic peptide (BNP) correlates with LV dysfunction in a variety of cardiac conditions $s^{4,5}$ and has been shown to predict heart failure and is related to LV filling pressure. Thus, determining the BNP level is now viewed as a useful clinical tool for the screening and monitoring of heart failure 6 Nevertheless, the interpretation of BNP levels in patients with lone AF and the usefulness of BNP measurements in these patients both remain unclear?-10 In this study, we evaluated plasma BNP levels in subjects with lone AF and compared them with subjects with sinus rhythm (SR) in order to identify the clinical and echocardiographic determinants of BNP level.

\section{Methods}

\section{Study Population}

The study was performed with institutional review board approval and informed consent from each subject. Patients referred to a single center for echocardiography who met the entry criteria were invited to participate. Ninety-six consecutive patients with either SR $(n=47)$ or AF $(n=49)$ were enrolled. All patients had preserved LV systolic func-

(Received August 4, 2005; revised manuscript received October 24, 2005; accepted November 1, 2005)

Cardiology Division, Kangnam Sacred Heart Hospital, Hallym University College of Medicine, Seoul, Republic of Korea

Mailing address: Sang Hak Lee, MD, Cardiology Division, Kangnam Sacred Heart Hospital, Hallym University College of Medicine, 948-1 Daelim 1-dong, Youngdeungpo-gu, Seoul, 150-950, Republic of Korea.

E-mail: shl1106@hallym.ac.kr tion. Medications were allowed for hypertension and heart rate control. Clinical data were obtained by complete review of each patient's medical record, history taking, physical examination, and transthoracic echocardiography. Coronary angiography was performed in selected cases. Exclusion criteria were the presence of symptomatic heart failure, valvular disease, congenital heart disease, hypertrophic cardiomyopathy, an LV ejection fraction $\leq 45 \%$, a permanent pacemaker, paroxysmal $\mathrm{AF}$, uncontrolled heart rate ( $>100$ beats $/ \mathrm{min})$, more than moderate pulmonary disease, or thyroid dysfunction.

\section{Echocardiographic Evaluation}

Comprehensive transthoracic echocardiography was performed using commercially available equipment (Vivid 7 , GE Vingmed ultrasound, Horten, Norway). Standard Mmode, 2-dimensional and color Doppler imaging were performed in parasternal and apical views. Measurements were averaged for 3 cardiac cycles in subjects with SR and for 10 cardiac cycles in patients with AF. LV ejection fraction was measured using modified Simpson's rule. Left atrial (LA) volume was assessed by the modified biplane area-length method ${ }^{11}$ and was indexed to body surface area. Peak early mitral inflow velocity (E) was measured using pulsed wave Doppler method, by placing the sample volume at the level of the mitral valve leaflet tips. The tissue Doppler derived diastolic mitral annular velocity (E') was measured from the septal corner of the mitral annulus in the apical 4-chamber view. Pulmonary artery systolic pressure was calculated from tricuspid regurgitant flow velocity as determined in continuous wave Doppler mode! ${ }^{2}$

Measurement of Plasma BNP Levels

Blood samples were taken at the time of echocardiogra- 
Table 1 Baseline Characteristics of the Study Group

\begin{tabular}{lccc}
\hline \hline & $\begin{array}{c}S R \\
(n=47)\end{array}$ & $\begin{array}{c}A F \\
(n=49)\end{array}$ & $p$ value \\
\hline Age (years) & $60 \pm 10$ & $63 \pm 10$ & 0.09 \\
Men & $27(58)$ & $33(66)$ & 0.45 \\
Duration of AF (months) & - & $35 \pm 47$ & - \\
Heart rate (beats/min) & $66 \pm 11$ & $75 \pm 14$ & 0.002 \\
Medical history & & & \\
$\quad$ Systemic hypertension & $30(63)$ & $29(58)$ & 0.66 \\
$\quad$ Diabetes mellitus & $4(8)$ & $17(34)$ & 0.003 \\
$\quad$ Current smoker & $9(20)$ & $11(22)$ & 0.83 \\
$\quad$ Hyperlipidemia & $2(5)$ & $8(16)$ & 0.12 \\
$\quad$ Renal failure & $1(3)$ & $0(0)$ & 0.28 \\
Medications & & & \\
$\quad$ ACE inhibitors & $14(30)$ & $28(56)$ & 0.03 \\
$\quad$-blockers & $6(13)$ & $27(54)$ & 0.001 \\
$\quad$ Ca channel blockers & $8(18)$ & $7(14)$ & 0.71 \\
$\quad$ Digitalis & $1(3)$ & $20(40)$ & 0.002 \\
Diuretics & $4(8)$ & $17(34)$ & 0.02 \\
\hline
\end{tabular}

Data are $n$ (percentage of group), mean $\pm S D$.

$S R$, sinus rhythm; $A F$, atrial fibrillation; $A C E$, angiotensin converting enzyme. Hyperlipidemia $=L D L$-cholesterol $\geq 130 \mathrm{mg} / \mathrm{dl}$; renal failure $=$ serum-creatinine $\geq 1.5 \mathrm{mg} / \mathrm{dl}$.

phy; a $2 \mathrm{ml}$ blood sample was taken from an antecubital vein after $10 \mathrm{~min}$ of supine rest, placed in a tube containing EDTA, and analyzed within $4 \mathrm{~h}$. Plasma BNP concentrations were determined using Triage BNP (Biosite Diagnostics, San Diego, CA, USA).

\section{Statistical Analysis}

Data are expressed as mean \pm SD. The patients were divided into 2 groups according to cardiac rhythm (ie, SR or AF). Differences between these 2 groups were assessed using chi-square statistics for categorical variables and Student's t-test for continuous variables. The BNP levels were compared with respect to hemodynamic parameter values (pulmonary artery systolic pressure, E/E' and LA volume index). Potential determinants of the BNP level were identified by univariate analyses, and all identified univariate predictors were then entered in a stepwise manner into a multivariate linear regression model. Correlations were also analyzed separately in the AF group. SPSS 12.0 (SPSS Inc, Chicago, IL, USA) was used for all statistical analyses.

\section{Results}

\section{Baseline Characteristics (Table 1)}

Of the 96 subjects, 60 were males and 36 were females and the age and gender of the subjects in the SR and AF groups were similar. Patients in the AF group were found to have a higher baseline heart rate $(\mathrm{p}=0.002)$ and were more likely to have diabetes; $(p=0.003)$ AF group patients were more often prescribed angiotensin converting enzyme inhibitors, $\beta$-blockers, digitalis, or diuretics.

\section{Echocardiographic Variables (Table 2)}

The AF group had a higher mean LA volume index than the SR group $(\mathrm{p}<0.001)$, but no difference was observed between the 2 groups in terms of; LV dimension, LV ejection fraction, LV mass index, or pulmonary artery systolic pressure. Although $E(p<0.001)$ and $E^{\prime}(p<0.001)$ were significantly higher in the AF group, the E/E' of the each group was similar.
Table 2 Echocardiographic Data

\begin{tabular}{lccc}
\hline \hline & $\begin{array}{c}S R \\
(n=47)\end{array}$ & $\begin{array}{c}A F \\
(n=49)\end{array}$ & p value \\
\hline LV ejection fraction $(\%)$ & $64 \pm 5$ & $62 \pm 7$ & 0.15 \\
LV end-diastolic dimension $(\mathrm{mm})$ & $48 \pm 5$ & $47 \pm 4$ & 0.10 \\
LV end-systolic dimension $(\mathrm{mm})$ & $31 \pm 4$ & $31 \pm 4$ & 0.59 \\
LV mass index $\left(\mathrm{g} / \mathrm{m}^{2}\right)$ & $90 \pm 19$ & $97 \pm 21$ & 0.13 \\
LA volume index $\left(\mathrm{ml}^{2} \mathrm{~m}^{2}\right)$ & $24 \pm 5$ & $39 \pm 13$ & $<0.001$ \\
PA systolic pressure $\left(\mathrm{mmHg}^{2}\right)$ & $27 \pm 6$ & $28 \pm 7$ & 0.35 \\
E $(\mathrm{cm} / \mathrm{s})$ & $64 \pm 15$ & $83 \pm 21$ & $<0.001$ \\
Deceleration time $(\mathrm{ms})$ & $199 \pm 39$ & $186 \pm 46$ & 0.19 \\
A $(\mathrm{cm} / \mathrm{s})$ & $70 \pm 17$ & - & - \\
$E^{\prime}(\mathrm{cm} / \mathrm{s})$ & $6.2 \pm 1.8$ & $8.2 \pm 2.2$ & $<0.001$ \\
E/E' & $11.2 \pm 4.2$ & $10.7 \pm 3.6$ & 0.56 \\
\hline
\end{tabular}

Data are $n$ (percentage of the group), mean $\pm S D$.

$S R$, sinus rhythm; $A F$, atrial fibrillation; $L V$, left ventricle; $L A$, left atrium; $P A$, pulmonary artery; E, early mitral inflow velocity; E', mitral annular velocity.

\section{Plasma BNP Levels}

Patients with AF had higher BNP levels than those with

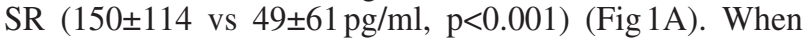
subjects in the 2 groups were stratified by pulmonary artery systolic pressure or E/E', significantly higher BNP levels were observed in the AF group (Fig 1B,C). However, BNP levels in the 2 groups were similar after matching the LA volume indexes (Fig 1D).

\section{Determinants of Plasma BNP Level}

The results of univariate and multivariate regression analyses are shown in Table 3. The univariate variables significantly associated with plasma BNP level in the study group were age, the presence of $\mathrm{AF}$, treatment with $\beta$-blockers or digitalis, LV mass index, LA volume index, pulmonary artery systolic pressure, E and E/E'. The independent determinants of BNP level as identified by multivariate linear regression analysis were LA volume index, $(\mathrm{r}=0.63, \mathrm{p}<$ $0.001)$ pulmonary artery systolic pressure, $(\mathrm{r}=0.45, \mathrm{p}=$ $0.006)$ and $E / E^{\prime}(r=0.36, p=0.04)$ Correlations between BNP level and LA volume index $(\mathrm{r}=0.65, \mathrm{p}=0.001)$ and with $E / E^{\prime}(r=0.38, p=0.03)$ were unaltered within the AF group (Fig 2A,B). Furthermore, the correlation between BNP level and LA volume index was significant even in subjects with $\mathrm{E} / \mathrm{E}^{\prime} \leq 10$ in the AF group ( $\mathrm{r}=0.92, \mathrm{p}=0.001$, $n=24$ ) in whom the E/E' ratio did not affect BNP levels.

\section{Discussion}

The present study shows (1) that the BNP levels were higher in the subjects with AF than with SR, (2) that the LA volume index, the pulmonary artery systolic pressure and the E/E' were independent predictors of a higher BNP level, (3) that these correlations between BNP level and LA volume index and E/E' were unaltered within the AF group, and (4) that individuals without an elevated E/E' also showed a correlation between BNP level and LA volume index.

Elevated BNP levels are known to correlate with LV systolic and diastolic dysfunction?,13,14 In addition, previous studies have shown that BNP levels correlate with LV filling pressure5,15 However, data regarding BNP levels and other neurohumoral changes in AF remain limited and controversial?,8,10 LV dysfunction frequently occurs in patients with $\mathrm{AF}^{2}$ and although the mechanisms for this have not been unveiled, myocardial energy depletion, myocar- 


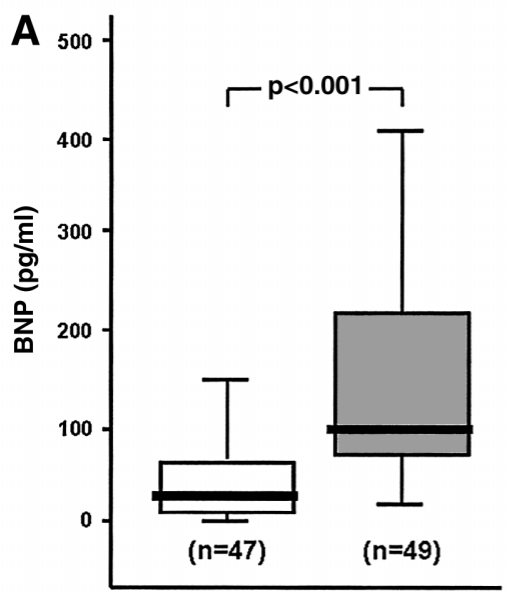

B

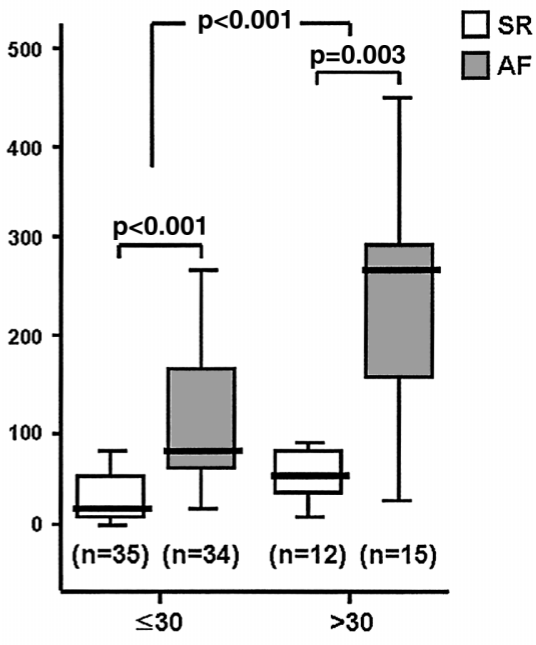

PA systolic pressure $(\mathrm{mmHg})$

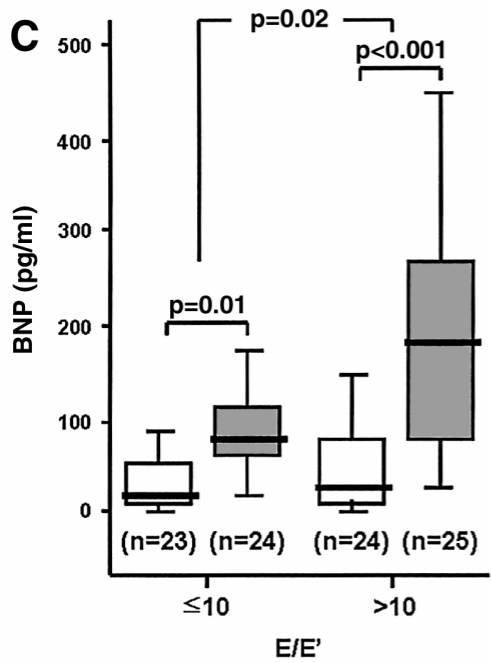

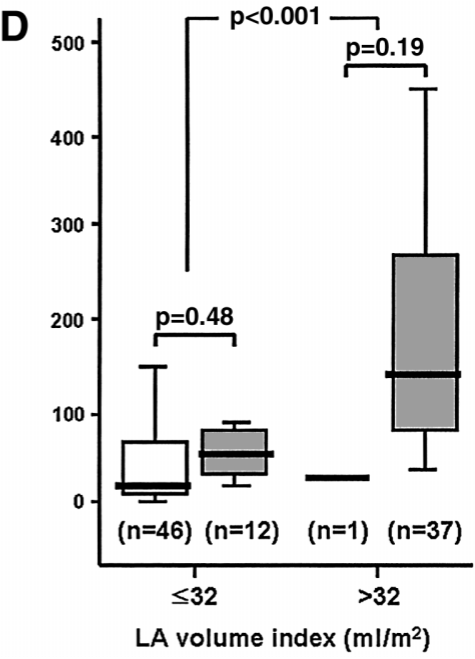

Fig 1. Box plot illustrating brain natriuretic peptide (BNP) levels in subjects with sinus rhythm or atrial fibrillation (AF). Patients with AF had higher BNP levels than those with sinus rhythm (A). When subjects in the 2 groups were stratified by pulmonary artery systolic pressure (B) or early mitral inflow velocity/mitral annular velocity (E/E') (C), significantly higher BNP levels were observed in the $\mathrm{AF}$ group. However, BNP levels in the 2 groups were similar after matching the left atrial (LA) volume indexes (D). PA, pulmonary artery; SR, sinus rhythm.

Table 3 Clinical and Echocardiographic Variables as Determinants of the Level of Brain Natriuretic Peptide (n=96)

\begin{tabular}{|c|c|c|c|c|c|c|c|}
\hline & \multicolumn{3}{|c|}{ Univariate regression analysis } & \multicolumn{4}{|c|}{ Multivariate regression analysis } \\
\hline & Coefficient $\beta$ ) & $S E$ & $p$ value & Coefficient $\beta$ ) & $S E$ & $r$ & $p$ value \\
\hline Sex & 27.4 & 23.1 & 0.24 & - & - & - & $N S$ \\
\hline Age & 2.9 & 1.1 & 0.009 & - & - & - & $N S$ \\
\hline Presence of $A F$ & 99.6 & 21.1 & $<0.001$ & - & - & - & $N S$ \\
\hline Baseline heart rate & 1.0 & 0.9 & 0.25 & - & - & - & $N S$ \\
\hline$\beta$-blockers & 52.2 & 25.6 & 0.04 & - & - & - & $N S$ \\
\hline Digitalis & 72.0 & 29.9 & 0.02 & - & - & - & $N S$ \\
\hline ACE inhibitors & 28.6 & 27.3 & 0.30 & - & - & - & $N S$ \\
\hline LV ejection fraction & 0.9 & 1.8 & 0.85 & - & - & - & $N S$ \\
\hline LV mass index & 1.7 & 0.6 & 0.006 & - & - & - & $N S$ \\
\hline$L A$ volume index & 6.0 & 0.7 & $<0.001$ & 5.2 & 1.0 & 0.63 & $<0.001$ \\
\hline PA systolic pressure & 7.0 & 1.6 & $<0.001$ & 5.3 & 1.8 & 0.45 & 0.006 \\
\hline E & 2.2 & 0.5 & $<0.001$ & - & - & - & $N S$ \\
\hline$E^{\prime}$ & 3.3 & 5.0 & 0.52 & - & - & - & $N S$ \\
\hline$E / E^{\prime}$ & 8.0 & 2.8 & 0.006 & 6.9 & 3.4 & 0.36 & 0.04 \\
\hline
\end{tabular}

$A F$, atrial fibrillation; $A C E$, angiotensin converting enzyme; $L V$, left ventricle; $L A$, left atrium; $P A$, pulmonary artery; E, early mitral inflow velocity; $E^{\prime}$, mitral annular velocity.

dial ischemia, abnormal calcium regulation, extracellular matrix remodeling, ${ }^{16}$ and sympathetic activation have been reported to occur in patients with AF!7 Although Silvet et $\mathrm{al}^{8}$ and Ellinor et $\mathrm{al}^{10}$ demonstrated that $\mathrm{AF}$ is predictive of an elevated BNP, Rossi et al reported that plasma BNP levels are not independently associated with AF? However, the latter report included many patients with LV systolic dysfunction and mitral regurgitation, which made their study population heterogeneous. Moreover, they did not assess tissue Doppler derived mitral annular velocity, which might have reflected LV diastolic function. We enrolled a more uniform patient population to eliminate 

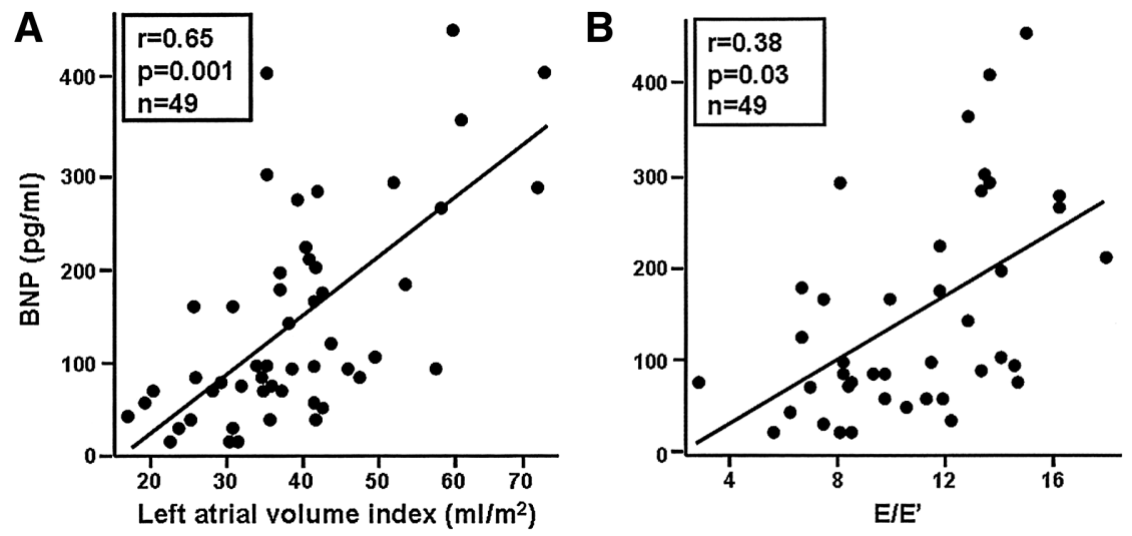

Fig2. Scatter plots depicting the relationship between brain natriuretic peptide (BNP) level and (A) left atrial volume index or (B) early mitral inflow velocity/mitral annular velocity (E/E') in subjects with atrial fibrillation.

bias from the structural and functional status of the heart and assessed mitral annular velocity in all patients. In our study, the BNP levels were higher in patients with AF than in those with SR $(150 \pm 114$ vs $49 \pm 61 \mathrm{pg} / \mathrm{ml}, \mathrm{p}<0.001)$, and

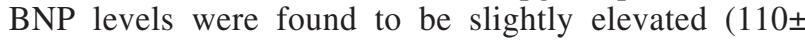
$95 \mathrm{pg} / \mathrm{ml}$ ) in $\mathrm{AF}$ patients even when the E/E' ratio was lower than 10. Although BNP levels were not found to be affected by the presence of AF after controlling for other independent determinants (Fig 1D, Table 3), it is possible that there is a causal relationship and collinearity between $\mathrm{AF}$ and the LA volume index $(\mathrm{r}=0.62, \mathrm{p}<0.001)$, which would explains the lack of an independent association between the presence of AF and the BNP levels in our analysis. Moreover, it is hard to conclude that there was no significant difference of BNP level between the SR and AF groups after matching LA volume index, using data from only $1 \mathrm{SR}$ patient with LA volume index $>32 \mathrm{ml} / \mathrm{m}^{2}$.

The E/E' ratio, which is a combination of tissue Dopplerderived diastolic mitral annular velocity (E') and pulsed Doppler early mitral inflow velocity $(\mathrm{E})$, is well correlated with invasively measured LV filling pressure5 Recently, this ratio was used as a reliable and reproducible parameter for the noninvasive estimation of LV filling pressure! ${ }^{8}$ Nagueh et al revealed a relationship between Doppler echocardiographic parameters and LV filling pressure in patients with AF ${ }^{19}$ More recently, Oyama et al reported that the Doppler-derived index, the ratio of transmitral peak E-wave velocity to color flow propagation, correlated well with neurohumoral and hemodynamic parameters in patients with $\mathrm{AF}^{20}$ However, the role of tissue Doppler echocardiography in AF has not been completely established. In the present study, E/E' was found to be independently correlated with BNP level in AF patients. Our results confirm the association between E/E', a noninvasively measured parameter determined by tissue Doppler, and BNP levels in patients with AF. Nevertheless, this correlation was not significant in those with an E/E' $<10$, which concords with the findings of Mak et al who reported a lack of correlation between BNP levels and E/E' in patients with normal LV function 14 Accordingly, elevated BNP levels in such individuals can not be explained by $\mathrm{E} / \mathrm{E}$ ' ratio alone.

A recent report suggested that the LA volume index is related to cardiovascular risk in patients without valvular disease or atrial arrhythmia, ${ }^{21}$ and that LA volume index is of prognostic significance in patients with acute myocardial infarction.22 The LA volume index reflects increased LA pressure and may represent chronic LV diastolic dysfunction. ${ }^{21-23}$ Whereas most diastolic parameters are influenced by acute hemodynamic changes, LA volume also reflects the long-term exposure of the LA to abnormal LV diastolic function and filling pressures. In the present study, although the mean E/E' of the 2 groups was similar, the mean LA volume index was higher in subjects with $\mathrm{AF}$ than in those with SR $\left(39 \pm 13\right.$ vs $\left.24 \pm 5 \mathrm{ml} / \mathrm{m}^{2}, \mathrm{p}<0.001\right)$. Thus LA enlargement can not be explained on the basis LV diastolic dysfunction alone, but should also be based on the presence of AF. Sanfillippo et al found that atrial size increases with time in patients with AF, even in the absence of other causes of atrial enlargement $24 \mathrm{AF}$, with its irregular ventricular cycle length, decreases cardiac output, increases pulmonary capillary wedge pressure ${ }^{25}$ and increases atrial pressure ${ }^{26}$ Moreover, the loss of atrial contribution to LV filling, and a rapid rate with shortened diastolic filling times, mandates an elevated atrial pressure?

We observed that the relationship between BNP level and LA volume index was independent of E/E' and pulmonary pressure in the present subjects. The elevation of the BNP level in individuals with a larger LA volume is partly a consequence of an elevated LV filling pressure and thus, of an elevated E/E', but the correlation between BNP level and LA volume in patients with AF observed in the present study cannot be explained by this mechanism, especially in individuals with an $\mathrm{E} / \mathrm{E}^{\prime} \leq 10$. Prior studies on $\mathrm{AF}$ have suggested that BNP may be in part atrially delivered,,10,27 Furthermore, Luchner et al reported that, during early LV dysfunction, BNP mRNA and tissue BNP are markedly increased in the LA, but remain at the limit of detection in the LV 28 Increased production of BNP in a stretched LA exposed to elevated pressure may explain the correlation between BNP level and LA volume in our study.

\section{Study Limitations}

First, an invasive study was not performed to evaluate the relationship between hemodynamic profiles and BNP level. Second, we measured the mitral annular velocity only from the septal corner of the annulus. Although the septal $\mathrm{E}^{\prime}$ is less reliable in patients with adjacent wall motion abnormalities, none of our subjects had this problem. Third, our data did not include the atrial natriuretic peptide level, which might have helped to understand the hemodynamic changes in AF. In addition, some assessment of the R-R variability would have been useful. We could then have evaluated the relationship between the regularity of cardiac rhythm and the BNP level.

\section{Conclusions}

The BNP levels were higher in subjects with lone AF 
than in those with SR; however, the influence of AF itself on the BNP level is unclear in this study. BNP levels were found to be significantly correlated with LA volume index and tissue Doppler-derived E/E' in patients with lone AF, after adjusting for clinical and echocardiographic variables, which indicates that BNP levels may reflect early LV dysfunction and LA enlargement in this patient population.

\section{Acknowledgment}

Korea.

\section{References}

1. Chugh SS, Blackshear JL, Shen WK, Hammill SC, Gersh BJ. Epidemiology and natural history of atrial fibrillation: Clinical implications. J Am Coll Cardiol 2001; 37: 371-378.

2. Grogan M, Smith HC, Gersh BJ, Wood DL. Left ventricular dysfunction due to atrial fibrillation in patients initially believed to have idiopathic dilated cardiomyopathy. Am J Cardiol 1992; 69: 1570 1573.

3. Cha YM, Redfield MM, Shen WK, Gersh BJ. Atrial fibrillation and ventricular dysfunction: A vicious electromechanical cycle. Circulation 2004; 109: 2839-2843.

4. Lubien E, DeMaria A, Krishnaswamy P, Clopton P, Koon J, Kazanegra R, et al. Utility of B-natriuretic peptide in detecting diastolic dysfunction: Comparison with Doppler velocity recordings. Circulation 2002; 105: 595-601.

5. Dokainish H, Zoghbi WA, Lakkis NM, Al-Bakshy F, Dhir M, Quinones MA, et al. Optimal noninvasive assessment of left ventricular filling pressure: A comparison of tissue Doppler echocardiography and B-type natriuretic peptide in patients with pulmonary artery catheters. Circulation 2004; 109: 2432-2439.

6. Rodeheffer RJ. Measuring plasma B-type natriuretic peptide in heart failure: Good to go in 2004? J Am Coll Cardiol 2004; 44: 740-749.

7. Rossi A, Enriquez-Sarano M, Burnett JC Jr, Lerman A, Abel MD, Seward JB. Natriuretic peptide levels in atrial fibrillation: A prospective hormonal and Doppler-echocardiographic study. J Am Coll Cardiol 2000; 35: 1256-1262.

8. Silvet H, Young-Xu Y, Walleigh D, Ravid S. Brain natriuretic peptide is elevated in outpatients with atrial fibrillation. Am J Cardiol 2003; 92: $1124-1127$.

9. Wozakowska-Kaplon. Effect of sinus rhythm restoration on plasma brain natriuretic peptide in patients with atrial fibrillation. $A m J$ Cardiol 2004; 93: 1555-1558.

10. Ellinor PT, Low AF, Patton KK, Shea MA, MacRae CA. Discordant atrial natriuretic peptide and brain natriuretic peptide levels in lone atrial fibrillation. J Am Coll Cardiol 2005; 45: 82-86.

11. Appleton CP, Galloway JM, Gonzalez MS, Gaballa M, Basnight MA. Estimation of left ventricular filling pressure using two-dimensional and Doppler echocardiography in adult patients with cardiac disease: Additional value of analyzing left atrial size, left atrial ejection fraction and the difference in duration of pulmonary venous and mitral flow velocity at atrial contraction. J Am Coll Cardiol 1993; 22: $1972-1982$.

12. Currie PJ, Seward JB, Chan KL, Fyfe DA, Hagler DJ, Mair DD, et al. Continuous wave Doppler determination of right ventricular pressure:
A simultaneous Doppler catheterization study in 127 patients. $J$ Am Coll Cardiol 1985; 6: 750-756.

13. Troughton RW, Prior DL, Pereira JJ, Martin M, Fogarty A, Morehead $\mathrm{A}$, et al. Plasma B-type natriuretic peptide levels in systolic heart failure. J Am Coll Cardiol 2004; 43: 416-422.

14. Mak GS, DeMaria A, Clopton P, Maisel AS. Utility of B-natriuretic peptide in the evaluation of left ventricular diastolic function: Comparison with tissue Doppler imaging recordings. Am Heart J 2004; 148: $895-902$.

15. Maeda K, Tsutamoto T, Wada A, Hisanaga T, Kinoshita M. Plasma BNP as a biochemical marker of high LVEDP in patients with symptomatic left ventricular dysfunction. Am Heart J 1998; 135: 825832.

16. Shinbane JS, Wood MA, Jensen DN, Ellenbogen KA, Fitzpatrick AP, Scheinman MM. Tachycardia-induced cardiomyopathy: A review of animal models and clinical studies. J Am Coll Cardiol 1997; 29: $709-715$.

17. Wasmund SL, Li JM, Page RL, Joglar JA, Kowal RC, Smith ML, et al. Effect of atrial fibrillation and an irregular ventricular response on sympathetic nerve activity in human subjects. Circulation 2003; 107: $2011-2015$.

18. Hadano Y, Murata K, Liu J, Oyama R, Harada N, Okuda S, et al. Can transthoracic Doppler echocardiography predict the discrepancy between left ventricular end-diastolic pressure and mean pulmonary capillary wedge pressure in patients with heart failure? Circ J 2005; 69: $432-438$

19. Nagueh SF, Kopelen HA, Quinones MA. Assessment of left ventricular filling pressure by Doppler in the presence of atrial fibrillation. Circulation 1996; 94: 2138-2145.

20. Oyama R, Murata K, Tanaka N, Takaki A, Ueda K, Liu J, et al. Is the ratio of transmitral peak E-wave velocity to color flow propagation velocity useful for evaluating the severity of heart failure in atrial fibrillation? Circ J 2004; 68: 1132 - 1138 .

21. Tsang TS, Barnes ME, Gersh BJ, Bailey KR, Seward JB. Left atrial volume as a morphophysiologic expression of left ventricular diastolic dysfunction and relation to cardiovascular risk burden. Am J Cardiol 2002; 90: 1284-1289.

22. Møller JE, Hillis GS, Oh JK, Seward JB, Reeder GS, Wright RS, et al. Left atrial volume: A powerful predictor of survival after acute myocardial infarction. Circulation 2003; 107: 2207-2212.

23. Pritchett AM, Mahoney DW, Jacobsen SJ, Rodeheffer RJ, Karon BL, Redfield MM. Diastolic dysfunction and left atrial volume: A population study. J Am Coll Cardiol 2005; 45: 87-92.

24. Sanfillippo AJ, Abascal VM, Sheehan M, Oertel LB, Harrigan P, Hughes RA, et al. Atrial enlargement as a consequence of atrial fibrillation. Circulation 1990; 82: 792-797.

25. Clark DM, Plumb VJ, Epstein AE, Kay GN. Hemodynamic effects of an irregular sequence of ventricular cycle lengths during atrial fibrillation. J Am Coll Cardiol 1997; 30: 1039-1045.

26. White CW, Kerber RE, Weiss HR, Marcus ML. The effects of atrial fibrillation on atrial pressure-volume and flow relationships. Circ Res 1982; 51: 205-215.

27. Inoue S, Murakami Y, Sano K, Katoh H, Shimada T. Atrium as a source of brain natriuretic polypeptide in patients with atrial fibrillation. J Card Fail 2000; 6: 92-96.

28. Luchner A, Stevens TL, Borgeson DD, Redfield M, Wei CM, Rorter JG, et al. Differential atrial and ventricular expression of myocardial BNP during evolution of heart failure. Am J Physiol 1998; 274: H1683-H1689. 